\title{
Design e Antropologia: ensaio de correspondência
}

\author{
Design and Anthropology: rehearsal of correspondence
}

Anastassakis, Zoy

\section{Resumo}

O workshop discute algumas das correspondências criadas por meio de encontros entre campos de saber tais como design e antropologia. Retomando aspectos históricos da aproximação entre essas duas áreas de conhecimento, aponta também para o debate teórico-metodológico que se formula em torno dela, identificando e comentando algumas das categorias e noções que atualizam esses encontros. Em seguida, apresenta as questões que atravessam o emergente campo identificado pelo termo design anthropology, elencando pesquisadores, projetos, publicações e instituições envolvidas. Dessa forma, o workshop se propõe como um primeiro contato com os temas caros àqueles que vem experimentar colocar em correspondência antropologia e design.

Palavras Chave: design anthropology; correspondências; interdisciplinaridade.

\begin{abstract}
The workshop discusses some of the correspondences created through encounters between fields of knowledge such as Design and Anthropology. Taking up historical aspects of the approximation between these two areas of knowledge, it also points to the theoretical-methodological debate that is formulated around it, identifying and commenting on some of the categories and notions that update these meetings. It then presents the issues that cross the emerging field identified by the term design anthropology, listing researchers, projects, publications and institutions involved. In this way, the workshop proposes as a first contact with the themes that matters to those who come to try to put in correspondence Anthropology and Design.
\end{abstract}

Keywords: design anthropology; correspondence; interdisciplinarity. 


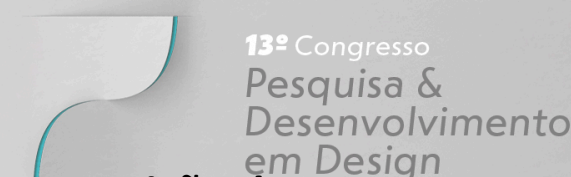

Descrição da proposta

O workshop pretende introduzir os participantes no histórico das relações entre Design e Antropologia (D\&A), apresentando-os aos temas e questões que compõem essa aproximação. Para isso, será organizado em três partes: 1) exposição da proponente do workshop sobre histórico da relação entre as duas disciplinas, principais pesquisadores, temas, questões, obras e instituições; 2) exercício de identificação de temas recorrentes em meio às principais referências bibliográficas produzidas sobre design e antropologia nos últimos anos; 3) apresentação dos trabalhos de identificação de temáticas recorrentes na bibliografia sobre as relações entre design e antropologia, e debate final.

\section{Relevância}

Antes de mais nada, deve-se ressaltar que o cerne da experiência que o workshop propõe é a própria experimentação teórico-metodológica dentro da emergente subárea de conhecimento nomeada, em inglês, como 'design anthropology', que se caracteriza pela exploração das possibilidades de combinação entre aportes teóricos e metodológicos consolidados nas duas disciplinas a serviço do equacionamento de questões complexas de pesquisa na área das ciências sociais e ciências sociais aplicadas, que não mais podem ser enfrentadas segundo uma perspectiva disciplinar unívoca e fechada. Dentre tais questões, ganha centralidade a emergência de novos e inusitados desafios socioculturais complexos.

Ora, se, historicamente, a antropologia tem se dedicado ao cuidado com a pesquisa densa e matizada sobre os diversos aspectos da vida dos seres humanos em sociedade a partir de uma perspectiva engajada, em que pesquisador e pesquisado estabelecem relações que são também sociais; e se o design tem se ocupado do encaminhamento projetual de soluções para a melhoria da vida em sociedade, notadamente nos contextos sociais complexos, urbanos, industriais ou pósindustriais; então, as duas disciplinas combinadas apontam para uma complementaridade teórica, que é também de métodos e procedimentos, complementaridade essa que se configura como estratégica hoje na academia.

A combinação interdisciplinar entre design e antropologia apresenta tal rendimento acadêmico exatamente por combinar as características mais proeminentes de cada uma das disciplinas a serviço do enfrentamento de questões sociais, somando o entendimento engajado e aprofundado, perspectiva teórico-metodológica que organiza a disciplina da antropologia, à antecipação de alternativas e soluções que se materializam na forma de comunicação, interfaces, produtos ou serviços, áreas que organizam a disciplina do design. Partindo de aporte teórico e de procedimentos metodológicos consolidados nas duas disciplinas, a emergente subárea de conhecimento acima apresentada é hoje campo fértil para pesquisas nas grandes áreas das ciências sociais e ciências sociais aplicadas, como apontado pela bibliografia enumerada nesta proposta de workshop.

No quadro internacional, encontra proeminência a Dinamarca, que, ancorada em sua liderança histórica nos estudos de design democrático, participativo, engajado e social, tem liderado a consolidação de uma rede fechada e global de pesquisadores na área, rede da qual esta proponente deste workshop é partícipe. No Brasil, contudo, a exploração em torno da combinação entre design e antropologia é assunto inédito, não tendo recebido atenção acadêmica até há pouco, limitando-se as pesquisas nesta área ao trabalho desta proponente, que coordena na IES $X$ o Laboratório Y e também da Prof. Dra. Raquel Gomes Noronha, que na Universidade Federal do 
Maranhão coordena QN Núcleo de Pesquisas em Imagem, Design e Antropologia (NIDA).

em Design

\section{Qualidade técnica}

Os conceitos e técnicas que vem sendo experimentados pelos pesquisadores relacionados ao campo de relações que aproxima Design e Antropologia serão apresentados aos participantes pela ministrante na primeira parte do workshop. Em seguida, os participantes serão convidados a identificar, nas principais publicações da área, as temáticas e questões recorrentes aos estudos que aproximam Design e Antropologia. A partir da análise dos sumários dessas publicações, os participantes realizarão exercícios de organização dos temas recorrentes, identificando e agrupando termos similares e correlatos. Esses exercícios serão apresentados a todos na forma de diagramas conceituais, desenhados pelos membros de cada grupo com papel, cola e canetas. Assim, com ferramentas básicas, e aproveitando o tempo de duração do workshop, os participantes entrarão em contato prático com as temáticas que organizam as pesquisas que aproximam Design e Antropologia, desenvolvendo dispositivos de conversação (Anastassakis, Szaniecki, 2016), provótipos (Lenskjold, 2011) ou artefatos dialógicos (Gatt, Ingold, 2013), ferramentas metodológicas próprias ao campo do design anthropology.

\section{Descrição da estrutura e equipamentos necessários}

Serão necessários projetor, mesas, cadeiras, folhas de papel, tesouras, canetas coloridas, cola e fita adesiva. Também fotocópias de sumários de livros sobre design anthropology fornecidos pela proponente, em número de um conjunto de dez fotocópias em preto e branco por participante.

\section{Duração}

3 horas.

\section{Referências}

ANASTASSAKIS, Z; SZANIECKI, B. "Conversation dispositifs: towards a transdisciplinary design anthropological approach". In: SMITH, R. C.; VANGKILDE, K. T.; KJAERSGAARD, M. G.; OTTO, T.; HALSE, J.; BINDER, T. (Eds.) Design Anthropological Futures. London: Bloomsbury, 2016, p. 121138.

BINDER, T.; MICHELIS, G. et al. Design Things. Cambridge: MIT Press, 2011.

BINDER, T.; BRANDT, E.; EHN, P.; HALSE, J. “Democratic design experiments: between parliament and laboratory". In: CoDesign: International Journal of CoCreation in Design and the Arts, Volume 11, Issue 3 - 4 , 2015 (Special Issue: Designing Things Together: Intersections of Co - Design and Actor - Network Theory ), p. 152 - 165.

CLARKE, A. (Ed.). Design Anthropology. Object culture in the 21st Century. Wien: Springer-Verlag, 2011.

GATT, .; INGOLD, T. From Description to Correspondence: Anthropology in Real Time. In: GUNN, W.; OTTO, T.; SMITH, R. C. Design and Anthropology: Theory and Practice. Londres, Nova lorque: Bloomsbury Academic, 2013. pp. 139-158. 
GUNN, W.; OTTO, T.' \& Smith, R. C. (Eds.). Design Anthropology: theory and practice. London and New York: Bloomsbury, 2013.

GUNN, W.; DONOVAN, J. (Eds.). Design and Anthropology. Surrey and Burlington: Ashgate, 2012.

HALSE, J.; BRANDT, E.; CLARK, B.; BINDER, T. (Eds.). Rehearsing the future. Copenhagen: The Danish Design School Press, 2010.

INGOLD, T. The life of lines. London and New York: Routledge, 2015.

INGOLD, T. Making: anthropology, archeology, art and architecture. London and New York: Routledge, 2013.

INGOLD, T. Being Alive: essays on movement, knowledge and description. London and New York: Routledge, 2011.

INGOLD, T. The Perception of the Environment: essays on livelihood, dwelling and skill. London and New York: Routledge, 2000.

LATOUR, B. Reassembling the social: an introduction to actor-network theory. Oxford University Press, 2005.

LATOUR, B. "A Cautious Prometheus? A few steps toward a philosophy of design (with special attention to Peter Sloterdijk)". In: Networks of Design. Cornwall, 2008.

LATOUR, B. "An attempt at a "Compositionist Manifesto". In: New Literary History 41, p. 471-490.

LENSKJOLD, T. U. Accounts for a critical artifacts approach to design anthropology. Nordic Design Research Conference, Helsinki, 2011, 09 p.

MARCUS, G. E.; RABINOW, P. Designs for an anthropology of the contemporary. Durham and London: Duke University Press, 2008.

SUCHMAN, L. "Anthropological relocations and the limits of design". In: Annual Review of Anthropology, 40. 2011, p. 01-18.

WASSON, C. "Ethnography in the field of design". In: Human Organization, vol. 59, n. 4. Society for Applied Anthropology, 2000, p. 377-388. 
